\title{
O CULTO AO CORPO E SUAS FORMAS DE PROPAGAÇÃO NA REDE SOCIAL FACEBOOK: implicações para a Educação Física Escolar
}

Ana Carolina Copellini Rigoni?

Felipe Gustavo Barros Nunes?

Karina das Mercês Fonseca ${ }^{3}$

\section{RESUMO}

O modo como a mídia influencia na construção de padrões de beleza corporal não é uma novidade. A rápida evolução tecnológica das últimas décadas promoveu importantes transformações na maneira como acessamos as informações e nos comunicamos com os outros. As redes sociais e, principalmente o Facebook, são exemplos disso. Compreendendo o Facebook como uma agência estimuladora do "culto ao corpo", mas em alguns momentos como promotora de resistência a ele, procuramos analisar de que maneira algumas práticas como dietas, intervenções cirúrgicas, consumo de cosméticos, bem como os próprios modelos de corpo aparecem publicadas nesta rede social - em forma de imagens ou discursos - e como, consequentemente, elas influenciam a vida das mulheres que a utilizam. Além disso, buscamos apresentar algumas reflexões sobre as implicações deste fenômeno na e para as aulas de Educação Física.

Palavras-chave: meios de comunicação . Culto ao Corpo. Educação Física.

1 Doutora em Ciências do Movimento Humano. Professora da Universidade Metodista de Piracicaba (UNIMEP). Piracicaba/São Paulo, Brasil. E-mail: anacarolinarigoni@yahoo.com.br

2 Mestrando em Ciências do Movimento Humano. Universidade Metodista de Piracicaba (UNIMEP). Piracicaba/ São Paulo, Brasil. E-mail: felipegbn@yahoo.com.br

3 Licenciada em Educação Física. Universidade Federal de São João del Rei (UFSJ). São João Del Rei/Minas Gerais, Brasil. E-mail: kfonseca68@yahoo.com

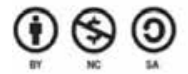


THE CULT OF THE BODY AND THEIR PROPAGATION FORMS IN SOCIAL NETWORK FACEBOOK: implications for School Physical Education

\begin{abstract}
The mode how media influence in the construction of body beauty standards is not new. A fast technological developments of the last decades has promoted significant changes in the way we access information and we communicate with others. Social networks and mainly facebook are examples of that. Comprising the facebook as a stimulating agency of the "cult of the body", but in a few moments as a promoter of resistance to it, we try to analyze how some practices such as diet, the surgical interventions, the consumption of cosmetics; well as the models themselves body appears published in this social network - In the form of images and speeches - and how, consequently, they influence women's lives who use it. Besides that, we seek to present some thoughts on the implications of this phenomenon in and for physical education classes.
\end{abstract}

Keywords: Media. Cult of the body. Physical Education.

\title{
EL CULTO AL CUERPO Y SUS FORMAS DE DIFUSIÓN EN LA RED SOCIAL FACEBOOK: implicaciones para la Educación Física Escolar
}

\section{RESUMEN}

La forma en que los medios influyen en la construcción de estándares de belleza corporal no es nueva. La rápida evolución tecnológica de las últimas décadas ha promovido cambios significativos en la forma en que accedemos a la información y nos comunicamos con los demás. Las redes sociales y en especial el Facebook, son ejemplos del mismo. Comprendiendo la facebook como una agencia estimulante del "culto al cuerpo", pero a veces como promotora de la Resistencia a este, tratamos de analizar cómo aparecen publicadas algunas prácticas tales como la dieta, las intervenciones quirúrgicas, el consumo de cosméticos, así como los modelos corporales propios en esta rede social - en forma de imágenes o discursos - y cómo, en consecuencia, influyen en la vida de las mujeres que lo utilizan.

Palabras clave: Medios de comunicación. Culto al cuerpo. Educación Física. 


\section{INTRODUÇÃO}

Inúmeros estudos já analisaram o modo como a mídia influencia os gostos e comportamentos humanos. Somos cotidianamente bombardeados por imagens e textos que educam nossos corpos e nos mobilizam no sentido de tentarmos alcançar padrões estéticos, que são divulgados como superiores e necessários. A novidade não reside no fato de constatarmos o poder da mídia na educação das gerações, mas talvez no modo como ela mesma se adequa e se moderniza em suas formas. A cada dia uma nova tecnologia surge no mercado, transformando o modo como acessamos as informações e, principalmente, o modo como nos comunicamos com os outros.

As redes sociais (virtuais) atingiram o mundo em escala incomensurável, alcançando, inclusive, pessoas mais velhas e que possuíam pouca intimidade com a internet e com o mundo virtual. O facebook ${ }^{4}$ é, sem dúvida a rede social mais utilizada no mundo. O site é gratuito e qualquer pessoa (que se declare com mais de 13 anos de idade) pode se registrar. Por ser gerido com receita proveniente de publicidade, o facebook é um eficiente meio de divulgação de imagens e propagandas. Além da publicidade formal, circulam no site inúmeras imagens, fotos, textos e comentários de cunho individual que acreditamos exercer marcada influência nos modos de vida de seus usuários.

Partindo deste pressuposto, este estudo buscou compreender e analisar a forma como as imagens e os discursos circulam no facebook, produzindo conhecimentos e agenciando a construção corporal de mulheres ${ }^{5}$ que consomem as informações nele veiculadas. Compreendendo o facebook como uma agência estimuladora do "culto ao corpo" ${ }^{6}$, mas em alguns momentos como resistência a ele, procuramos analisar a maneira pela qual algumas práticas como as dietas, as intervenções cirúrgicas, o consumo de cosméticos e remédios, bem como os próprios modelos de corpo aparecem publicadas nesta rede social e como, consequentemente, elas influenciam a vida das mulheres que a utilizam. Além disso, buscamos apresentar algumas breves reflexões sobre as implicações deste fenômeno no âmbito escolar e suas possíveis relações com as aulas de Educação Física (EF).

A metodologia utilizada seguiu os princípios básicos da pesquisa qualitativa, de caráter documental. Conforme Gil (1994), a pesquisa documental é fundamentalmente elaborada a partir de material que não recebeu tratamento analítico. Diversos autores defendem a ideia de que hoje, o mundo virtual torna-se ferramenta de pesquisa. Segundo Flick (2009), a internet assume o papel de meio por meio do qual se coletam dados de pesquisa. Para o autor, uma pesquisa qualitativa no mundo virtual analisa os textos e materiais compartilhados por usuários para descobrir quem, de fato, utiliza a internet e como usa.

4 Segundo divulgação do site Wikipédia, o facebook, que é um site de rede social, lançado em 2004, atingiu a marca de 1 bilhão de usuários em 2012, sendo considerado até hoje a maior rede social do mundo.

5 É preciso explicar que a escolha pelas mulheres não foi aleatória. Antes de iniciarmos as análises que aqui apresentamos resumidamente, fizemos uma pesquisa inicial, na qual constatamos que a maior parte dos usuários que comentava e compartilhava este tipo de post eram mulheres.

6 Assim como Castro (2007), estamos utilizando o conceito de "culto ao corpo" como uma preocupação exagerada com os cuidados corporais, promovida, em grande parte, pela mídia e pela indústria capitalista. 
Como aponta Santos (2009a), diante das aceleradas mudanças da sociedade da informação é necessário ter flexibilidade para a descoberta de formas diferentes de realizar o trabalho científico, incorporando as novas tecnologias desenvolvidas no mundo virtual, em especial, os recursos digitais e audiovisuais. É preciso, segundo a autora, explorar adequadamente suas potencialidades, propiciando inovações nos procedimentos de investigação social. Se a grande preocupação de pesquisadores que utilizam ferramentas virtuais é a autenticidade e rigor das informações, num caso como o nosso, por se tratar de uma pesquisa que coleta dados numa rede como o facebook, essa preocupação é irrelevante, já que está em jogo não o rigor crítico dos dados, mas os significados atribuídos por aqueles que os compartilham, sendo estes verídicos ou não.

Ainda em relação a metodologia, realizamos a coleta de dados no site mencionado, durante o período de agosto de 2013 a janeiro de 2014. Como estratégia metodológica registramos um segundo perfil ${ }^{7}$, que foi utilizado exclusivamente durante o trabalho. Este segundo perfil passou a ser gerenciado pelos pesquisadores que, ao longo da coleta de dados foram selecionando os conteúdos de acordo com os interesses da pesquisa. Este perfil foi criado para servir de arquivo e concentrar num único espaço virtual todas as postagens que interessavam à análise. Como o facebook é uma rede muito dinâmica e o número de postagens é muito elevado, um perfil específico, que concentrasse somente o material de análise da pesquisa, foi fundamental para que as informações de nosso interesse não se perdessem na "enxurrada" de postagens diárias que circulam num perfil real.

Para evitar problemas éticos, neste segundo perfil, adicionamos somente usuários que optaram, na rede facebook, por manterem todos os seus dados públicos. O que significa, segundo o portal de privacidade do site em questão, que todos os dados por eles compartilhados tornam-se informações públicas, pois ao criar uma conta na rede e ao preencher suas configurações de privacidade o usuário aceita esta condição ${ }^{8}$. Foi tomando estes cuidados que todas as mensagens e imagens compartilhadas nos perfis originais dos pesquisadores e que eram relevantes à pesquisa eram diretamente enviadas (compartilhadas) e arquivadas neste segundo perfil, para serem, posteriormente, analisadas. Esta foi a forma mais adequada que encontramos para manter um arquivo com todos os dados, incluindo não só a postagem principal (texto, vídeo e imagem), mas os comentários feitos em cada postagem, bem como o número de "curtidas" e de compartilhamentos.

Em relação aos critérios de coleta de dados, optamos pela seleção de postagens que continham a presença do corpo de forma direta ou indireta. Selecionamos arquivos

7 O perfil é o espaço destinado aos dados pessoais. Nele as pessoas registram seu nome de usuário, adicionam uma ou mais fotos e preenchem informações como: endereço, trabalho, relacionamento, contato, etc. O usuário pode escolher entre manter o seu perfil privado ou torna-lo público, o que significa permitir o acesso (visita) de outros usuários. Quando nos referimos a criação de um segundo perfil, significa que um dos pesquisadores criou um perfil além daquele de uso pessoal.

8 Ver no link: https://www.facebook.com/help/203805466323736

9 O botão de "curtir" é um recurso onde os usuários podem gostar de certos conteúdos, tais como atualizações de status, comentários, fotos, links compartilhados por amigos, e propagandas. 
que veiculavam corpos "em forma" 10, corpos "gordos", corpos "magros", corpos em atividade física, imagens de pessoas famosas, imagens que zombavam de alguns tipos de corpos, cabelos e roupas, arquivos com dicas de beleza, dieta, cuidados com os cabelos e com a pele, entre outros. Além da veiculação do corpo, utilizamos, como critério de inclusão, o número de compartilhamentos e "curtidas" que cada postagem havia recebido até o momento. Ao longo da coleta salvamos as que apresentaram maior repercussão e, depois, para a realização da análise, selecionamos as mais "curtidas" e compartilhadas e excluímos as que tiveram menos adesão ou repercussão. A amostra inicial foi composta por 49 postagens, das quais 20 foram selecionadas para a análise. No entanto, para viabilizar a produção deste artigo, tivemos que reduzir a seleção ainda mais. Trabalhamos aqui, portanto, com a análise de apenas 10 imagens, que estão divididas em 2 categorias.

As categorias que aqui apresentamos não foram pré-definidas, mas surgiram ao longo da análise a partir de características que se repetiam e podiam ser alocadas e interpretadas numa mesma linha de pensamento. Como afirma Magnani (2009), as categorias não são construídas previamente, mas vão ganhando forma na medida em que emergem do próprio campo. Neste sentido, a estratégia de analise baseou-se não somente nos posts, mas também nos comentários publicados pelas pessoas que os compartilhavam. Tais opiniões, sejam em forma de brincadeiras ou comentários sérios, dizem muito a respeito do modo como este tipo de mídia educa as pessoas que dela compartilham.

\section{A MÍDIA E A IMAGEM}

Castro (2007), numa pesquisa em que analisou o culto ao corpo e os modos como duas revistas de grade circulação no país (Boa Forma e Corpo a Corpo) promovem a "indústria do corpo" e uma adoração por formas padronizadas, constatou que tais revistas "funcionam" porque possuem um tipo de discurso que busca convencer, mesclando argumentos estéticos e técnicos. Estas revistas, bem como grande parte da mídia, não só oferece modelos a serem seguidos como vende a fórmula para atingi-los. Guareschi e Biz (2005, p.45) analisando especificamente a televisão (TV), demonstram o papel central ocupado pela mídia na definição de nossas escolhas e na construção de nossas subjetividades. Os autores falam sobre como a relação de comunicação estabelecida pela TV é vertical, de cima para baixo, já que ela não faz perguntas, mas apenas fornece respostas.

Se o poder de tal personagem é indiscutível, o que dizer, então, das redes de comunicação contemporâneas, estabelecidas pela internet? As mídias virtuais, aparentemente mais livres do que a TV (que, representada por corporações, tem o poder de selecionar e transmitir apenas o que deseja), abarcam espaços e recursos que possibilitam a interação simultânea entre os sujeitos. Na "rede", cada sujeito é capaz de agenciar informações e seus modos de veiculação. Assim como a TV, mas mais dinâmica e diversificada, a internet utiliza um recurso visual altamente "educativo": a imagem. 
A imagem é utilizada pelas mídias como meio de construir subjetividades. Ela consegue, de modo geral, provocar em nós as mais diversas emoções e sentimentos. A imagem é capaz de causar maior impacto do que um texto escrito, pois por meio dela é possível conceber ideias (imagens mentais) de maneira mais rápida. O texto exige mais tempo, atenção e reflexão. A título de exemplo, Guareschi e Biz (2005, p. 45) citam a diferença de uma criança que somente assiste TV e outra que lê.

A criança que lê vai criando e imaginando em sua mente os personagens do texto: ela cria a figura da Chapeuzinho Vermelho, do lobo, do lenhador, do caçador; já a criança que vê TV recebe todos estes personagens prontos: determinada imagem, tal tamanho, cor, som, movimento. Ela não precisa se preocupar com nada, apenas em ver.

Featherstone (1991) coloca a imagem como principal recurso da cultura do consumo. Para ele, o consumo depende do cultivo de um vasto arsenal de imagens. A recompensa pelo trabalho exercido em função da aparência do corpo é compensada pela imagem de um "eu mais vendável", como afirma o autor. É justamente o corpo deste sujeito mais "vendável" que é exposto na mídia. No caso do facebook esse corpo chega ao usuário da rede social primeiramente em forma de propaganda, depois, ele mesmo garante, postando suas próprias fotos, a propagação de imagens que comprovam seu esforço e objetivo alcançados. A potência da imagem no processo de assimilação de ideias e informações torna a sua presença no facebook ainda mais eficaz. Além disso, na contemporaneidade, as imagens chegam até nós em velocidade e intensidade exacerbada. Se, há pouco tempo, para ter acesso à internet, era necessário um computador instalado num espaço específico, hoje temos acesso a ela, por exemplo, num ônibus em movimento. Tudo isto é possibilitado pela evolução tecnológica referente aos celulares, iPhones, $i P a d s^{11}$, etc. Tais tecnologias não são acessíveis somente às classes mais abastadas o que confirma a constatação de Guareschi e Biz (2005) quando estes afirmam que a mídia, nos dias atuais, é um fenômeno que perpassa todas as camadas da sociedade. Os autores ainda afirmam que "a informação é o novo modo de desenvolvimento responsável pela produtividade do sistema capitalista". As pessoas ou grupos que possuem a informação controlam o desenvolvimento, pois é ela que modifica a forma de relacionamento, aprendizado, meios de compra/aquisição de produtos, relações interpessoais, o consumo de informações e etc. Guareschi e Biz (2005, p.41) afirmam que "a comunicação constrói a realidade. Para os autores "algo existe ou deixa de existir, se é, ou não, midiado". Além de ditar o que existe ou não, atribui valor a esta "realidade existente", corroborando valores que nos incentivam a agir.

Se a mídia, de modo geral, elabora de maneira exemplar uma rede de relações e de comunicação, a internet tem, segundo Santos (2009b), modificado sobremaneira este fenômeno. As relações entre os indivíduos (usuários) mediadas pelo ciberespaço

11 iPad é um dispositivo semelhante ao tablete (tablet) produzido pela Apple Inc. O aparelho foi anunciado em 27 de janeiro de 2010, em uma conferência para imprensa no Yerba Buena Center for the Arts em São Francisco. São utilizados para navegar na internet e acessar as redes sociais. 
e agenciadas por computadores e celulares, se reconfiguram na contemporaneidade. As redes sociais virtuais, como afirmam Santaella e Lemos (2010), são revolucionarias porque permitem, além do acesso à informação - já proporcionado pelo rádio, pela TV, pelas mídias impressas, etc. -, a interação entre seus usuários. Além disso, o poder de selecionar os conteúdos de acordo com interesses pessoais fortalece ainda mais a ideia de "redes" de relação, agrupando gostos e conceitos. Neste sentido ela é um agente importante na formação de opinião e, consequentemente, na construção dos corpos. Braga (2009, p.1) ressalta o "destacado papel do discurso dos meios de comunicação de massa na constituição de uma cultura corporal específica, que em boa medida traduz nos corpos de seus membros os conflitos inerentes a esta concepção".

Se a imagem atinge a homens e mulheres na mesma proporção, é desproporcional a intensidade com que imagens e propagandas que visam definir certos padrões são voltadas às mulheres. No artigo "Fotografia e fetiche: um olhar sobre a imagem da mulher", Botti (2003, p.107) analisa a forma como a mulher é representada e o que a sua imagem gera na percepção dos homens. As imagens são usadas para colocar em evidência o corpo feminino, despertando emoções e "interesse sexual". Neste sentido, o desejo pelo "corpo perfeito", criado e aguçado pelas mídias, converge com os interesses de uma "indústria do corpo" que colocou não só a beleza, como a saúde a venda.

\section{IMAGENS, CONTEÚDOS E COMENTÁRIOS}

Selecionamos algumas das inúmeras imagens que foram analisadas na pesquisa para ilustrar este artigo. Analisamos, além das imagens, propriamente ditas, o conteúdo dos comentários publicados sobre cada uma das imagens. De nossa análise inicial resultaram duas grandes categorias, que retratam o modo de apropriação dos conteúdos acessados e veiculados pelas mulheres. A primeira categoria diz respeito a postagens que refletem uma crença na busca pelo corpo "ideal”. Nesta categoria se encaixam propagandas de remédios para emagrecer, dietas, pessoas famosas divulgando produtos relacionados à imagem corporal, etc. Na segunda categoria temos aquelas postagens que demonstram claramente uma posição contrária à ideologia do "corpo perfeito". Contrária, não porque as mulheres que compartilham tais mensagens se posicionam de maneira consciente sobre o tema, mas pelo fato de ironizarem os padrões e a própria forma de submissão a eles (o que, talvez, reflita, de algum modo, uma forma de consciência). O pressuposto é o de que, talvez, por não desejarem ou não conseguirem atingir os padrões impostos pela sociedade, estas mulheres utilizam estes referenciais como forma de piada (consigo mesmas) em relação ao peso corporal, aos cabelos mal arrumados, etc. Dentro destas duas categorias, ainda, encontramos comentários em dois sentidos. O primeiro diz respeito àqueles que parecem demonstrar apropriação acrítica dos padrões, ou seja, pessoas que consideram o conteúdo adequado e algo a ser seguido. $\mathrm{O}$ segundo se refere àqueles que demonstram uma posição crítica frente a eles, ou seja, pessoas que leem as postagens e, ao invés de aceitarem e se apropriarem delas, elaboram comentários críticos, que negam o conteúdo divulgado. 


\section{Categoria 1: a busca pelo corpo "ideal"}

As imagens que foram enquadradas nesta categoria demonstram claramente a crença num modelo padronizado de corpo. Tais postagens, ora ofertam meios para se chegar ao corpo desejado, ora criticam aqueles corpos que não se encaixam no padrão.

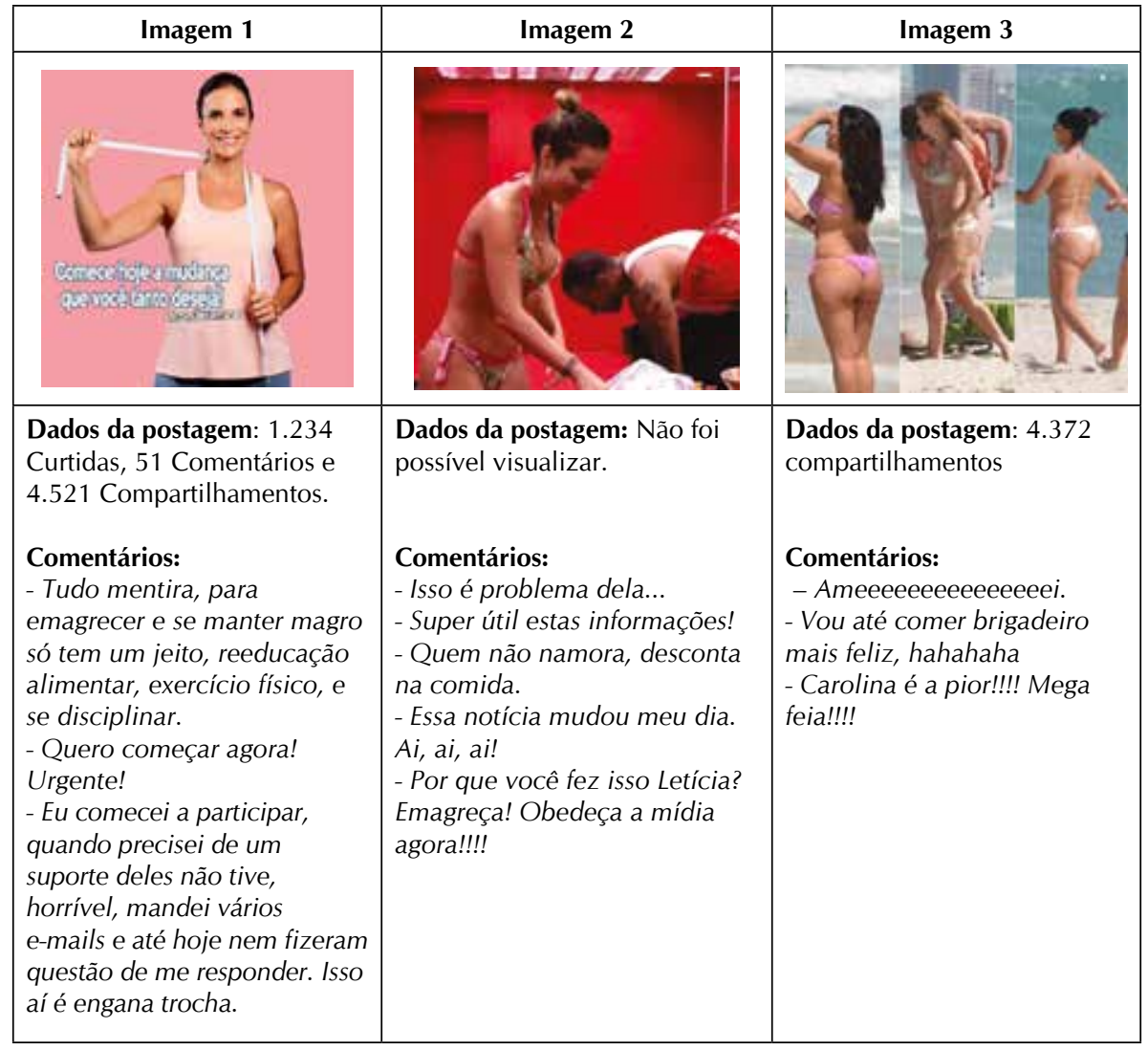

A imagem 1 foi divulgada como parte de um programa de reeducação alimentar, denominado "BodyChange 10 Semanas". O programa, disponível online, como o próprio nome já diz, tem duração de 10 semanas, o que significa uma promessa de rápida "transformação" do corpo em pouco tempo. A página, da qual esta foto foi compartilhada, veicula receitas de comidas saudáveis e produtos naturais que supostamente são usados pela cantora Ivete Sangalo. O corpo vendido é aquele que se parece com o da cantora. A página incita os usuários a descobrirem como ela se mantem atraente e mantem a energia. Percebe-se, como afirmou Rigoni (2013, p. 4), fazendo menção à Bourdieu que "atores, atrizes e 
famosos que possuem corpos que se encaixam nos padrões impostos pela mídia e pelo mercado parecem ser exemplos bem sucedidos na "economia dos bens simbólicos". Neste caso, o estímulo à reeducação alimentar se dá via a preocupação estética, sem considerar qualquer aspecto relativo à saúde e a qualidade de vida. A propaganda transmite a ideia de que a mudança é algo desejável, possível e acessível a todos. Este tipo de publicidade é peça-chave na sociedade de consumo, pois utiliza "exceções" que na maioria das vezes se distanciam da realidade, mas na propaganda aparecem como objetivos completamente atingíveis. Este tipo de anúncio (merchandising) é "agressivo" na medida em que transfere toda a responsabilidade do sucesso ou insucesso para os indivíduos que se dispõem a participar do processo. Além destas questões podemos analisar, ainda, o fato de que, neste tipo de programa, as sugestões alimentares prescritas, bem como os tipos de treinamento que requerem profissional especializado, são pouco acessíveis à grande parte da população.

Além disso, podemos constatar, como afirma Le Breton (2003), que o mal é biológico e o corpo torna-se um objeto a disposição da tecnologia, que é capaz de melhora-lo. O corpo torna-se "uma matéria-prima na qual se dilui a identidade pessoal". Neste caso, a imagem de uma pessoa famosa serve como referência para a construção de corpos de pessoas "comuns", pois como afirma o autor, o extremo contemporâneo dissocia o corpo da pessoa em si. O corpo de Natália (da primeira imagem) se constrói a partir do referencial do corpo de Ivete Sangalo (da segunda imagem). O sujeito (Natália), como afirma Le Breton (Idem, p.19), "representa um resto, tocado apenas indiretamente por meio de uma ação que visa a organicidade".

É possível, ainda, analisar mais alguns dados referentes a primeira imagem, como por exemplo, o último comentário, de uma mulher que comprou o pacote e que deixa claro que o serviço funciona bem até o momento da compra, mas deixa os clientes virtuais sem suporte ao longo do processo. Além de não ser oferecido o suporte necessário ao cliente, a empresa que vende o "pacote" não tem qualquer contato prévio com a pessoa que adquire o programa. Isto quer dizer que nenhuma avaliação física, psicológica ou médica é realizada nem antes, nem durante e nem depois do processo.

A imagem 2 foi retirada, por um usuário, da página do yahoo ${ }^{12}$, e compartilhada no facebook. Trata-se de uma reportagem sobre o "lado negativo do confinamento", de participantes do programa Big Brother Brasil13, transmitido pela Rede Globo de Televisão. A matéria é uma avaliação sobre quem ganhou mais peso durante e estadia na casa. Este programa é conhecido no Brasil e atinge grande parte da população. Afamado por selecionar apenas participantes jovens e dentro do padrão corporal estabelecido pela sociedade, o programa incentiva a exibição dos corpos em quase cem por cento do tempo e, ainda, estimula o envolvimento sentimental e sexual dos participantes, para "atrair" a audiência.

12 Página que é usada para divulgação de reportagens sobre esporte, notícias, celebridades, cinema, TV e é usada também como correio eletrônico ou e-mail, entre outras.

13 O Big Brother Brasil é um reality show muito famoso da TV brasileira. Trata-se de uma competição na qual diversos participantes ficam confinados numa casa, competindo entre eles por um prêmio em dinheiro. 
O programa, por si só, estabelece padrões aos milhares de crianças, jovens e adultos que o assistem. Mas nosso foco de análise aqui diz respeito às questões de gênero que circulam simbolicamente junto às imagens.

O foco da matéria foi o corpo feminino. É como se um homem pudesse engordar sem ser "condenado", mas uma mulher não. Mais do que isso, a matéria que dizer que uma mulher pode se sentir atraída por um homem mesmo depois dele ter engordado, mas o contrário não é possível. Como afirma Bourdieu (1999), o corpo feminino é objetificado pelo olhar e pelo discurso dos outros. Não é à toa que o autor se refere ao corpo feminino como "o corpo para o outro".

A imagem 3 foi publicada no facebook com a intenção de chamar a atenção para o fato de que as mulheres famosas também têm celulite. Ao postarem tal matéria, ainda que busquem demonstrar a normalidade no fato de mulheres, sem distinção, possuírem celulite, elas colocam a celulite como algo ruim, próximo a uma deformidade. É possível perceber isto por intermédio de um dos comentários sobre a atriz Carolina Dieckman (Carolina é a pior!!! Mega feia). Ou seja, é como se as usuárias do facebook que compartilharam a foto estivessem dizendo: ter celulite é feio, mas até as mulheres famosas têm. As usuárias sequer questionam o sentido da palavra "feio" e sobre os motivos pelos quais somos levados a achar um corpo com celulite algo ruim (já que é normal). Os padrões são incorporados de tal modo que naturalizamos a noção de "feio" e "belo".

\begin{tabular}{|c|c|}
\hline Imagem 4 & Imagem 5 \\
\hline 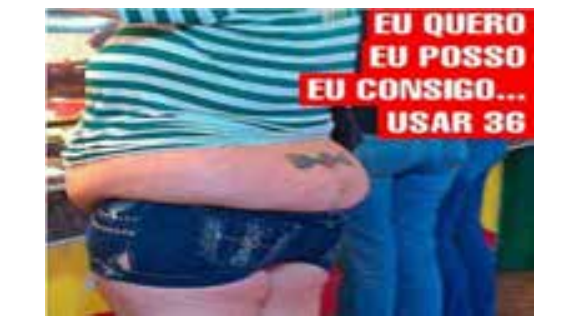 & 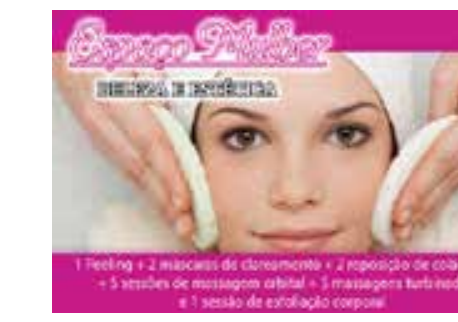 \\
\hline $\begin{array}{l}\text { Dados da postagem: não foi possível visualizar } \\
\text { Comentários: } \\
\text { - Purê de bunda! } \\
\text { - Puta falta de noção! } \\
\text { - Só por Jesus !!!! }\end{array}$ & $\begin{array}{l}\text { Dados da postagem: Não foi possível } \\
\text { visualizar }\end{array}$ \\
\hline
\end{tabular}

A imagem 4 foi postada no facebook com a seguinte frase: Eu quero, eu posso, eu consigo usar 36. Além disso ela foi compartilhada com a legenda: "Isso sim é força de vontade". No entanto, é possível perceber, através dos comentários publicados, que longe de ironizar os padrões e apresentar um tipo de resistência a eles, tal postagem é uma crítica "maldosa" à suposta falta de noção atribuída a pessoa da imagem. A severidade com que encaramos os padrões estabelecidos é tão rígida que se torna inconcebível uma pessoa 
"fora do modelo" vestir-se como bem desejar. Criamos um mundo onde algumas pessoas "têm permissão" e outras "restrições" para quase tudo, de acordo com a forma corporal. Esperamos, ainda, que cada um tenha consciência de seus limites e possibilidades, pois aqueles que não conhecem e não cumprem as exigências sociais são julgados e tornam-se alvo de piadas.

Outras reflexões podem ser elaboradas a partir desta imagem, como, por exemplo, sobre a questão da "moda especializada". Existem, hoje, fábricas e lojas especializadas na venda de roupas com tamanhos e marcas "adequados" para todos os tipos de público. As lojas se especializam em oferecer produtos para aqueles que possuem corpos que se encontram tanto dentro quanto fora dos padrões permitidos. Num passeio a qualquer shopping center podemos encontrar as lojas especializadas em roupas com tamanhos grandes e extragrandes. Estas lojas utilizam o termo plus size, como se desta forma estivessem sendo politicamente corretas e mais aptas ao mercado. Neste sentido, a sociedade não só separa e enquadra as pessoas segundo o tipo de roupas que cada uma pode ou deve utilizar, como hierarquiza os sujeitos. Substituir o termo gordo/gorda por plus size parece uma tentativa de minimizar as diferenças, já que o termo gordo/gorda, ao contrário de ser considerado um aspecto da identidade dos sujeitos é tido como pejorativo.

Para ampliarmos ainda mais a reflexão, pensemos em outro exemplo extremo, porém oposto, da padronização de corpos e, consequentemente, do enquadramento dos sujeitos. Para tanto, citamos como exemplo o caso de um Diretor Executivo de uma marca mundialmente famosa por suas T-Shirts esportivas quando este foi questionado a respeito de sua empresa não fabricar peças de tamanhos grandes $\left(X G\right.$ e XXG ${ }^{14}$. Sua resposta foi enfática ao dizer que a sua marca não fabrica roupas para serem utilizadas por pessoas gordas, e sim por pessoas magras e bonitas. Esta resposta rápida e convicta do diretor executivo, que parece não se importar com o fato de sua empresa promover a exclusão de uma camada significativa da sociedade, nos leva a refletir sobre o quanto os valores que são transmitidos pela sociedade de consumo atingem níveis exacerbados de preconceito e exclusão. Esta forma de ação, de setores do comércio, influencia de maneira significativa a vida dos sujeitos, que ao tentarem experimentar e comprar uma peça de roupa de lojas e empresas com este perfil, se deparam com a exclusão. É preciso considerar, ainda, a relação mecânica e imediata que o diretor estabelece entre magreza e beleza, impondo ao gordo o estereótipo da feiura.

Em relação a imagem 5, estes "pacotes de beleza" são muito comuns em sites de compra. Os usuários visualizam a promoção ao navegarem no facebook e, ao clicarem no link, são direcionadas ao site de compra. Os valores promocionais, aliados a rapidez e facilidade da compra otimizam o acesso aos diversos tratamentos estéticos. O corpo "natural" é corrigido pelos meios artificiais. O número de procedimentos oferecidos no pacote é uma pequena amostra daquilo que Le Breton chama de "corpo como acessório".

14 Ver link: http://veja.abril.com.br/noticia/economia/abercrombie-fitch-nao-quer-pessoas-gordasvestindo-sua-marca 


\begin{abstract}
Em nossas sociedades (...) o reservatório de conhecimento e de serviços à disposição dos indivíduos estendeu-se desmesuradamente. A maleabilidade de si, a plasticidade do corpo tornam-se lugares-comuns. A anatomia não é mais um destino, mas um acessório da presença, uma matéria-prima a modelar, a redefinir, a submeter ao design do momento (LE BRETON, 2003, p. 27).
\end{abstract}

Ou seja, é como se o corpo, representado na imagem, fosse uma coleção de pedaços (transformáveis ou substituíveis) e para cada pedaço/detalhe houvesse um preço (por isso a ideia de "pacote"). As imagens (postagens) apresentadas até aqui, são apenas alguns exemplos que consideramos fazer parte da primeira categoria de análise, relativa à assunção acrítica dos padrões via a sua propagação no facebook. Elas representam uma parcela ínfima das inúmeras publicações que circulam todos os dias pela rede social e que se referem a estética corporal, aos padrões de beleza e ao consumo relativo a eles. Chamamos de "acrítica" não por acreditarmos que todas as pessoas consomem ingenuamente os corpos vendidos. Não se trata de negar a agência dos usuários analisados, mas constatar um tipo de utilização do facebook na qual a grande maioria compactua com o "culto ao corpo" sem grandes reflexões. É preciso notar, no entanto, que mesmo representando uma maioria, em todos os posts encontramos comentários de resistência e crítica a apropriação automática e irrefletida dos padrões.

\title{
Categoria 2: contrariando a ideologia do "corpo perfeito"
}

Nesta segunda categoria temos aquelas postagens que demonstram claramente uma posição contrária à "ideologia do corpo perfeito". As imagens aparecem relacionadas, ainda que indiretamente, a críticas que buscam se rebelar contra os padrões impostos, ainda que em forma de piadas.

Esta imagem é a compilação de diversas fotos que foram compartilhadas individualmente no facebook. Elas foram retiradas de uma página denominada "Portal "Geledés: Instituto da Mulher Negra", que tem como pano de fundo a discussão sobre a relação da sociedade com a obesidade. A matéria apresenta uma tentativa de "desnaturalização" do corpo magro como melhor do que o gordo e levanta a bandeira do direito de todos a serem respeitados e tratados de forma igualitária.

Vigarello (2012), em As metamorfoses do Gordo, fala sobre a infelicidade a que estão condenados os obesos. O autor alerta para a coerção exercida diretamente sobre as carnes. Como se as formas do corpo devessem obedecer às manipulações mais exageradas. Se antes haviam os corpetes, as cintas e outros artifícios de contenção, que visavam a completa passividade do corpo, hoje vemos, além destes (que continuam atuais), as cirurgias plásticas, cirurgias de redução de estômago, de lipoaspiração, o uso de remédios para emagrecer, etc. Além disso, Vigarello alerta para a falsa relação entre a deformidade física e a deformidade moral, percebida através de comentários que cristalizam a imagem do gordo como preguiçoso, sem vergonha, sem vontade, etc. O autor ainda comenta 
sobre a estigmatização que tolera a gordura masculina, mas exige a magreza feminina. Não parece coincidência que as imagens analisadas sejam compartilhadas, em sua maioria, por mulheres.

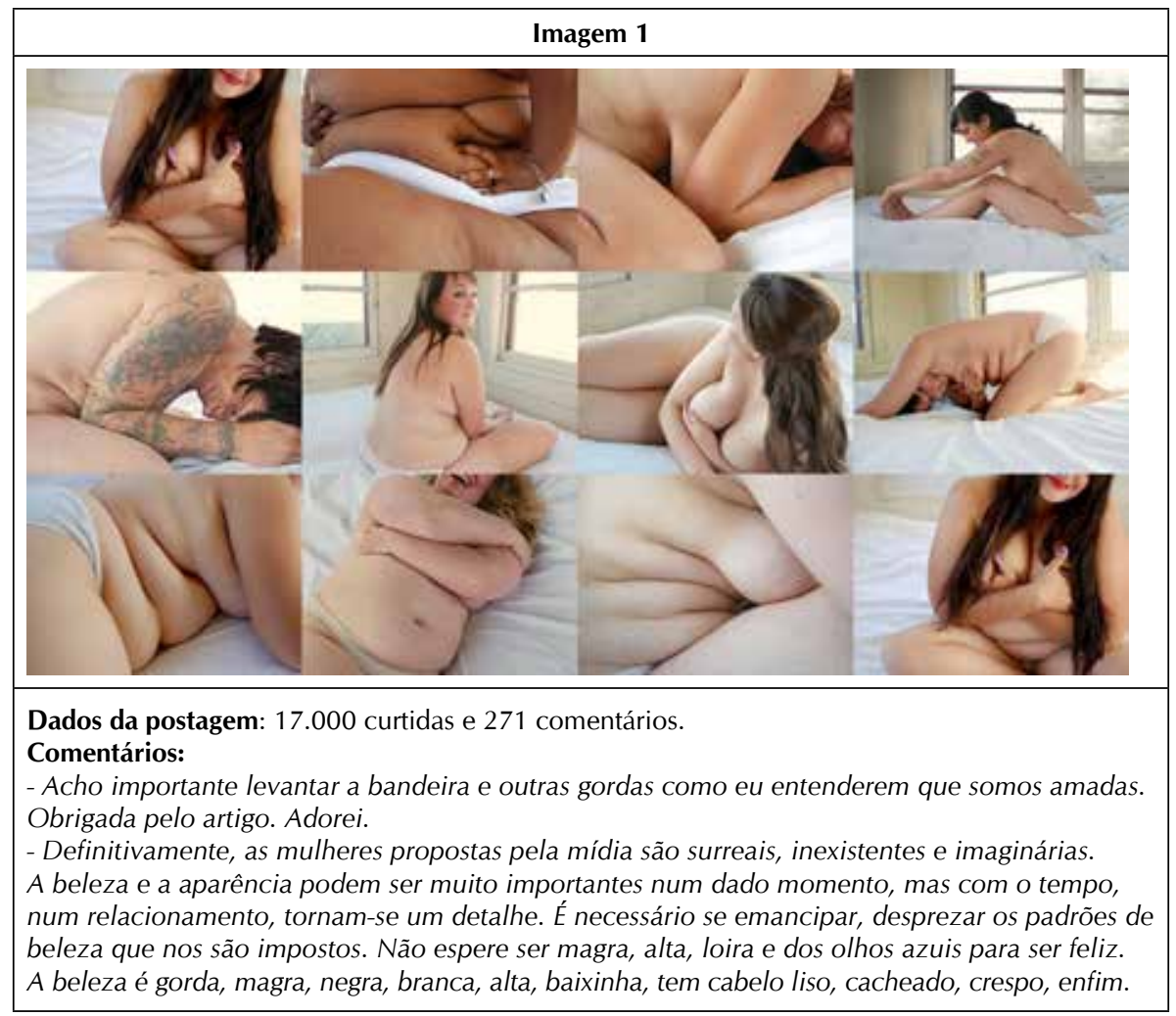

A página original das imagens 2 e 3 é de um site de vendas chamado "GymPass". O slogan da página é "diárias avulsas e diárias ilimitadas para as melhores academias perto de você". Oferecendo diárias a partir de $R \$ 8,90$ e pacotes para centenas de academias com mensalidade a partir de R\$59,90, o site "aposta" em piadas relacionadas ao peso e a falta de energia para se exercitar. É interessante notar que a maioria das pessoas compartiIha estas e outras imagens do mesmo gênero sem se dar conta de que a página é de uma academia de ginástica. O número de compartilhamentos é tão grande e acelerado que a origem e os objetivos iniciais se perdem. As imagens acabam sendo utilizadas apenas como forma de fazer piada com o próprio peso e com a própria preguiça. O objetivo do site parece ser o de lembrar àqueles que acessam o conteúdo que eles estão "perdendo tempo" e, consequentemente, de incita-los a fazer atividade física (claro, comprando os pacotes vendidos no site). 


\begin{tabular}{|c|c|c|}
\hline Imagem 2 & Imagem 3 & Imagem 4 \\
\hline $\begin{array}{l}\text { se vocé quiser seber se } \\
\text { reglneate esté gorda }\end{array}$ & $\begin{array}{l}\text { Um Fime de terror chamado: } \\
\text { "Lavei o cabelo e deixei } \\
\text { secar naturalmente }\end{array}$ & Como ter um "corpo de praia" \\
\hline 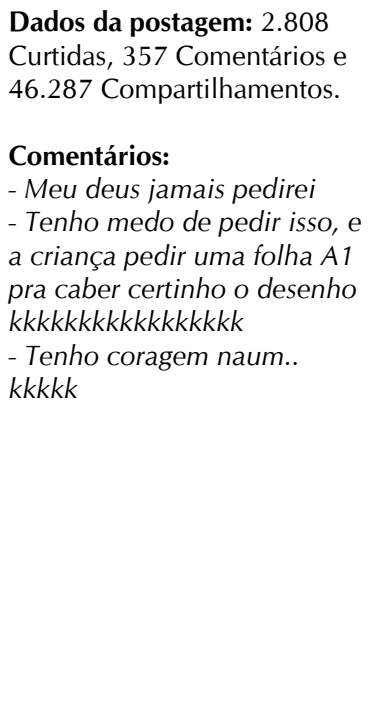 & $\begin{array}{l}\text { Dados da postagem: } 695 \\
\text { Curtidas, } 51 \text { Comentários e } \\
1.612 \text { Compartilhamentos } \\
\text { Comentários: } \\
\text { - Como escovar nesse calor, } \\
\text { não, não. Rsrsrsrs } \\
\text { - Oh gloria kkkkkkkkkk } \\
\text { - bem eu. Kkkkkk }\end{array}$ & $\begin{array}{l}\text { Dados da postagem: } 1.768 \\
\text { Curtidas, } 130 \text { Comentários e } \\
\text { 13.738Compartilhamentos. } \\
\text { Comentários: } \\
\text { - Mas ai tem photoshop, né? } \\
\text { - A beleza não tem forma. } \\
\text { - Essa ai ainda está bem na } \\
\text { fita! Com todas essas curvas e } \\
\text { quase sem barriga!!! -- Depois } \\
\text { dessa nem ouso pisar na } \\
\text { areia! } \\
\text { - E deixe para lá as magricelas, } \\
\text { pois quem gosta de osso é } \\
\text { cachorro!! } \\
\text { - "E deixe para lá as } \\
\text { magricelas, pois quem gosta } \\
\text { de osso é cachorro!!" Adoro } \\
\text { pessoas que combatem } \\
\text { o preconceito com mais } \\
\text { preconceito. }\end{array}$ \\
\hline
\end{tabular}

Se, para Castro (2007), o crescimento da indústria da beleza (academias de ginástica, cosméticos, cirurgias plásticas, etc.) indicava, na época da pesquisa (cerca de 10 anos atrás), a centralidade que o culto ao corpo assumia na sociedade contemporânea, cremos que as novas configurações, impulsionadas a cada dia pela rápida evolução tecnológica e de comunicação, confirmam não só a permanência como a exacerbação desta obsessão pela aparência.

A imagem 4 é uma tentativa de desnaturalizar estereótipo corporais, pois sugere que ninguém precisa se conformar e se enquadrar em um padrão específico. De certa, a imagem, apesar de concebida em forma de piada, apresenta uma resistência às obsessões estéticas. Ela parece interessante para a análise por diversas questões. Uma delas diz respeito à manipulação da imagem. Todos sabemos que as imagens de modelos e atrizes 
são trabalhadas no photoshop ${ }^{15}$, mesmo quando elas são magras, malhadas, bronzeadas, etc. No entanto, quando elas são divulgadas, poucas pessoas dão importância a possível manipulação nas formas físicas das atrizes e modelos. Mas, no caso de imagens com "muIheres gordinhas", é comum encontrarmos comentários criticando a utilização do photoshop. Como se corpos fora do padrão só pudessem ser expostos se forem minimamente corrigidos. Ideias do tipo: "se você vai à praia, use um maiô adequado para o seu corpo", são muito comuns. O termo "consciência corporal" é comumente utilizado, pelo senso comum, referindo-se à uma ideia equivocada de que ter consciência do próprio corpo é saber qual é a roupa mais adequada para ele, quais partes dele se pode exibir e quais partes de deve esconder. No caso do "gordo" é comum que somente seu rosto seja valorizado.

Estas questões são fundamentais principalmente quando presenciamos inúmeras mulheres (adolescentes e adultas) furtando-se de um dia na praia ou na piscina, por exemplo, simplesmente por vergonha de se exporem. Compartilhar imagens como estas ultimas, pode gerar tanto um sentimento de conformismo com o próprio corpo (com o próprio visual), como também pode gerar uma reflexão sobre vergonhas, medos e complexos de inferioridade produzidos pela sociedade.

\section{CONSIDERAÇÕES FINAIS}

Como afirma Le Breton (2003), à estética do belo a qualquer preço, junta-se o fundamentalismo da era virtual. O que significa que os modelos de corpo se propagam mais rápido e atingem um número sem igual de pessoas. Esta obsessão com a aparência, como afirma Castro (2007), pode ser vista como estratégia de construção da identidade, numa sociedade em que a fragmentação e a efemeridade tomam lugar numa configuração social cada vez mais complexa. A mídia, por sua vez, sabe muito bem como explorar tal situação.

E a mídia, instância socializadora das mais importantes na cultura contemporânea, explora este traço cultural, mediando a relação indivíduo-sociedade, sinalizando tendências, impondo e reciclando demandas dos mais diversos segmentos de leitores-expectadores (CASTRO, 2007, p.44).

Neste sentido, se os estudos sobre o "culto ao corpo" não são novos, o desenvolvimento da internet e das redes sociais, em suas configurações cada vez mais complexas, demanda novas reflexões sobre o tema. Se junto a estas questões ainda incluirmos suas interfaces com a escola e com a aula de Educação Física, no sentido de compreendermos como estes temas chegam até a escola e como nela são tratados, podemos produzir interessantes reflexões e, quem sabe, estratégias pedagógicas para lidar com o assunto.

O facebook e/ou outras mídias estão presentes na vida de grande parte dos alunos das escolas brasileiras. Mesmo aqueles que não são usuários desta rede social específica

15 Programa de computador que corrige, modifica e melhora as imagens. 
acessam, a todo momento, o "mundo virtual". Se em alguns posts os padrões divulgados são naturalizados e em outros vemos resistências a este processo de naturalização, isto significa que o facebook "educa" seus usuários de formas variadas. Para o "bem" ou para o "mal", ele está presente, assim como a escola, no processo de construção da identidade social de adolescentes e jovens.

Se nossos alunos, assim como os usuários analisados através dos comentários nos posts, acessam imagens como as exemplificadas e se apropriam das ideias que são vinculadas às imagens sem se questionar, incorporando desejos e ações na busca de "corpos ideais", devemos, enquanto professores, tornar as mídias virtuais tema de reflexão e ferramenta escolar. A disciplina de EF, neste caso, possui mais responsabilidade ainda, quando o que está em questão é o corpo e as práticas a ele relacionadas.

Partindo do princípio de que nossos alunos, tal qual os usuários do facebook aqui exemplificados, acreditam, por exemplo, que ter celulite é feio, que os "pacotes" de beleza funcionam, que os cabelos devem se enquadrar em formas aceitáveis, que ser "mais gordo" é sinônimo de feiura e de preguiça, etc., estas são questões que podem ser desconstruídas nas aulas de EF. Um professor consciente é capaz de ultrapassar este tipo de educação inconsciente do corpo, fazendo com que seus alunos superem a tirania a que estão sendo submetidos desde que nasceram. Uma aula de EF deve produzir e permitir certas reflexões sobre a construção sociocultural do corpo e sobre as influências que a mídia exerce neste quesito. Outro exemplo a ser tratado pedagogicamente diz respeito às questões de gênero. Se, como percebemos neste estudo, as mulheres parecem mais reféns dos padrões de beleza do que os homens, isso, por si só, já é assunto para a aula.

Ainda que haja a extrema necessidade de criticar a forma como a mídia e as redes sociais operam, não devemos perder de vista o seu papel e seu potencial como ferramenta pedagógica. Se, por um lado, a mídia exerce este papel "negativo", coercitivo e comercial, por outro, ela facilita o acesso à informação e o seu compartilhamento. Ao mesmo tempo que ela pode bitolar nossos alunos, ela é capaz de favorecer a disseminação de conteúdos que permitem estabelecer uma relação crítica com diversas questões. Neste sentido, nós professores, precisamos aprender a utilizar as mídias como ferramentas de ensino-aprendizagem.

Autores contemporâneos têm alertado para a contribuição das novas tecnologias na melhoria da aprendizagem. Silva (2013) critica a resistência por parte de professores à chamada inclusão digital. Para a autora, a "tecnofobia" só prejudica o desenvolvimento da aprendizagem. Possuir domínio das tecnologias e do mundo virtual pode permitir ao professor a construção de nossas interações e conhecimentos dos alunos sobre questões que ele normalmente acessa sem a mediação pedagógica. Se, como afirmam Diniz et al (2012, p.184), "os veículos midiáticos possuem grande poder principalmente sobre os jovens, que dedicam parte considerável de seu tempo para suas diversas formas de manifestação" e, consequentemente, isto vai para dentro da escola e se reflete nos estilos, desejos e emoções dos alunos, a escola precisa contribuir para uma leitura mais crítica desta realidade. É preciso ensinar aos alunos, que já aderiram redes de relações configuradas no ciberespaço, a criticar e resistir à manipulação midiática. 
No caso do facebook, o próprio fato de ser uma rede na qual é possível comentar livremente as diversas postagens já permite certa resistência, certa crítica a determinados padrões. É preciso aprendermos a ensinar através das mídias, mas, acima de tudo, ensinarmos sobre seu uso consciente. Os nossos alunos precisam compreender o modo como a mídia, incluindo as redes sociais, têm poder no que diz respeito à educação do corpo. Como afirma Betti (2003, p.97):

\begin{abstract}
"Se cabe à Educação Física introduzir e integrar o aluno na cultura corporal de movimento, há que se considerar que: (...) o consumo de informações e imagens proveniente das mídias faz parte da cultura corporal contemporânea, e, portanto, não pode ser ignorada; pelo contrário, deve ser objeto e meio de educação, visando instrumentalizar o aluno para manter uma relação crítica e criativa com as mídias (BETTI, 2003: 97-98).
\end{abstract}

Uma utilização mais “inteligente" das redes sociais é possível. Mas, para que possamos pensar numa possível intervenção, nós professores de EF, precisamos estar atentos às condições históricas e ao desenvolvimento tecnológico que tornaram propícia a adesão dos usuários de redes sociais. É preciso compreender o contexto social, econômico e cultural no qual estamos inseridos. Precisamos, ainda, pensar em estratégias que possibilitem uma nova elaboração e ressignificação do conhecimento propagado de forma fácil e rápida pelas mídias virtuais. Isto possibilitará uma educação que desloque os alunos do plano do senso comum, permitindo-lhes o acesso às informações produzidas na e pela mídia de maneira mais autônoma e crítica.

\title{
REFERÊNCIAS
}

BETTI, M. Imagem e ação: a televisão e a Educação Física escolar. In: BETTI, Mauro (org.). Educação Física e Mídia: novos olhares outras práticas. São Paulo: Hucitec, 2003. BOURDIEU, P. A Dominação masculina. Rio de Janeiro, Bertrand Brasil, 1999.

BOTTI, M. M. V. Fotografia e fetiche: um olhar sobre a imagem da mulher. Cadernos Pagu (21) 2003: pp.103-131.

BRAGA, A. Corpo, mídia e cultura. Razón y Palabra, v. 69, p. VII - 22009

CASTRO, A. L. Culto ao corpo e sociedade: mídia, estilos de vida e cultura de consumo. 2.ed. São Paulo: Annablume, 2007.

DINIZ, I. K. S.; RODRIGUES, H. A.; DARIDO, S. C. Os usos da mídia em aulas de Educação Física escolar: possibilidades e dificuldades. Movimento, Porto Alegre, v. 18, n. 03, p. 183-202, jul/set, 2012.

FEATHERSTONE, M. O Curso da Vida: corpo, cultura e imagens do processo de envelhecimento. In: DEBERT, G. G. Antropologia e Velhice: textos didáticos. IFCH/ UNICAMP, março, 1993.

FLICK, Uwe. Uma introdução à pesquisa qualitativa. Porto Alegre: Bookman, 2004. 
GIL, A.C. Métodos e técnicas de pesquisa social. 4 ed. São Paulo: Atlas, 1994. 207p.

GUARESCHI, P. A; BIZ, O. Mídia, educação e cidadania: tudo o que você deve saber sobre mídia. Petrópolis, RJ: Vozes, 2005.

LE BRETON, D. Adeus ao Corpo: Antropologia e Sociedade. Campinas, SP: Papirus, 2003.

MAGNANI, J. G. C. De perto e de dentro: notas para uma etnografia urbana. In: NAU - Núcleo de Antropologia Urbana da USP. Disponível em: http://www.n-a-u.org. Acessado em: 04/05/2009.

RIGONI, A. C. C. Corpo e Religião: Aproximações Possíveis. Anais do XVIII Congresso Brasileiro de Ciências do Esporte e V Congresso Internacional do Esporte, Brasília, ago. 2013.

SANTAELLA, L.; LEMOS, R. Redes sociais digitais: a cognição conectiva do Twitter. São Paulo: Paulus, 2010.

SANTOS, T. S. Do artesanato intelectual ao contexto virtual: ferramentas metodológicas para a pesquisa social. Sociologias, n.22 Porto Alegre July/Dec. 2009 (a).

SANTOS, V. L. C.; SANTOS, J. E. As redes sociais digitais e sua influência na sociedade e educação contemporâneas. HOLOS, Ano 30, Vol. 6, 2014 (b).

SILVA, L. A. O uso pedagógico de mídias na escola: práticas inovadoras. Revista Eletrônica de Educação de Alagoas. v.1, n.1, 2013.

VIGARELLO, G. As Metamorfoses do Gordo: história da obesidade no Ocidente da Idade Média ao século XX. Petrópolis, RJ, Vozes, 2012.

Recebido em: outubro/2016 Aprovado em: janeiro/2017 